\title{
Caesarean scar pregnancy managed noninvasively with system methotrexate
}

\begin{abstract}
A woman with eight weeks amenorrhea and bleeding per vaginum was diagnosed with caesarean scar pregnancy. Since her S. HCG level was less than 10,000 miu/ $\mathrm{ml}$, she was taken up for systemic multiple dose methotrexate regimens. The patient was administered 4 doses of methotrexate on alternate days. S.HCG level declined gradually and at 21 days her S.HCG level was zero. The grave emergency thus was managed very simply on an outpatient basis.
\end{abstract}

Keywords: caesarean scar pregnancy, serum human chorionic gonadotrophin, methotrexate
Volume 4 Issue 6 - 2018

Deepti Jain

Department of Designation Consultant Obgyn, University of

Chhotu, India

Correspondence: Deepti Jain, Department of Designation

Consultant Obgyn, University of Chhotu, Ram Hospital

Address 10, II Huda Complex Rohtak Haryana, India, Tel

+9194665944I I, Email deeptijain62@gmail.com

Received: August 02, 2017| Published: November 19, 2018
Abbreviations: SHCG, serum human chronic gonadotrophin; MXT, methotrexate

\section{Introduction}

A higher rate of caeserean section in the past few decades has led to an increase in the incidence of caeserean scar pregnancy. It is a serious emergency and presents often with one or more near fatal bouts of uterine hemorrhage. Caeserean scar pregnancy is a rare type of ectopic pregnancy where the embryo implants in the myometrium of lower segment at the site of previous caesarean section scar. The possible mechanism of this condition is the penetration of the blastocyst through a micro tubular tract between the caesarean scar and endometrial canal and thereby implantation into the myometrium. The clinicians are still not aware of the presentation and frequently misdiagnose it as a case of incomplete abortion. In one report as the dilator was put for an attempt to suction and evacuation, patient bled profusely and went into shock and developed obstetric collapse. ${ }^{1}$

\section{Case description}

A 30 year woman with 8 weeks pregnancy presented with bleeding pervaginum for 1 day. On ultrasonography, no gestation sac was seen in the uterine cavity. However a hypo echoic area $17 \times 15 \mathrm{~mm}$, the gestation sac, was visible in the anterior myometrium of the lower segment of uterus, at the site of previous caesarean scar (Figure 1).

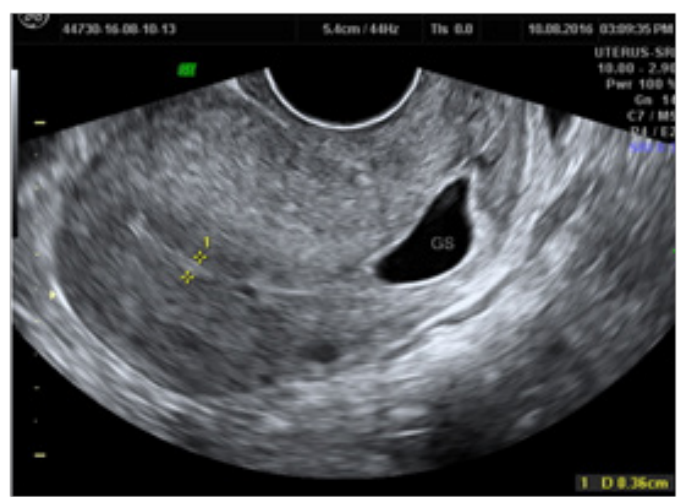

Figure I Empty uterine cavity and gestation sac seen in lower uterine segment.
A fetal node could be visualized in the sac and on doppler study blood flow was visible around the gestation sac (Figure $2 \& 3$ ).

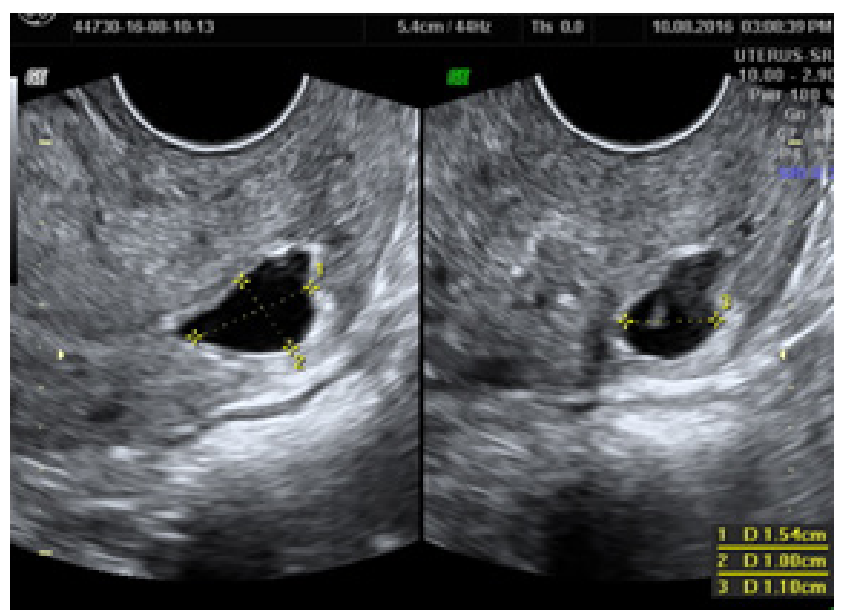

Figure 2 Fetal node visible in the gestation sac.

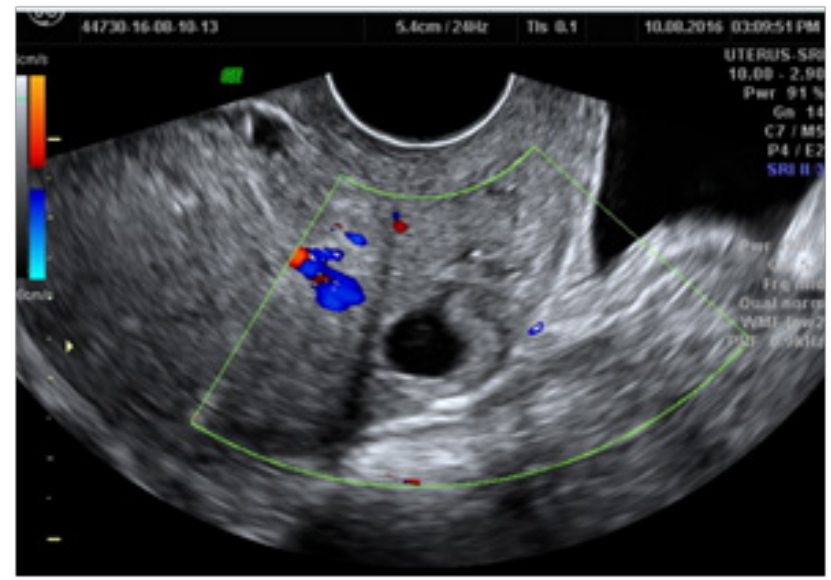

Figure 3 Perigestational blood flow seen on color Doppler.

Serum HCG assay was done and found to be $5623.0 \mathrm{miu} / \mathrm{ml}$. A prior history of caeserean section and the ultrasonic pictures helped us to make a diagnosis of Caeserean scar pregnancy. Jurcovic's criteria 
for diagnosis of caesarean scar pregnancy on ultrasound, as stated below were considered and fulfilled in this case:

i. An empty uterine cavity with a clearly demonstrable endometrial.

ii. The gestational sac visualized as a "double ring" sign in the anterior part of isthmus of uterus.

iii. Presence of gestational sac embedded and surrounded by myometrium.

iv. Thin or absent myometrium between gestational sac and the bladder.

v. Peritrophoblastic flow around the gestation sac. ${ }^{2}$

As the S.HCG was value below $10,000 \mathrm{miu} / \mathrm{ml}$; conservative treatment with intramuscular methotrexate in multiple dose regimens was begun. Four injections of methotrexate were given on days $1,3,5,7$ in a dose of $1 \mathrm{mg} / \mathrm{kg}$ body weight. Leucovorin rescue $0.1 \mathrm{mg} /$ $\mathrm{kg}$ body weight was given on alternate days. On day 3, S.HCG had declined to $4718.8 \mathrm{miu} / \mathrm{ml}$, and on day 8 it was $2419.2 \mathrm{miu} / \mathrm{ml}$. Serum HCG decreased to $405.64 \mathrm{miu} / \mathrm{ml}$ on day 14 and became 0 on day 21 . The gradual decline and then the complete absence of S.HCG implied a complete resolution of the scar pregnancy (Table 1).

Table I S.HCG measurement and values

\begin{tabular}{ll}
\hline Day of S.HCG measurement & S.HCG value in mi.u./ml \\
\hline Day I & $5623.0 \mathrm{mi} . u . / \mathrm{ml}$ \\
Day 3 & $4718.8 \mathrm{mi} . u / \mathrm{ml}$ \\
Day 8 & $2419.2 \mathrm{mi} . \mathrm{u} . / \mathrm{ml}$ \\
Day I4 & $405.1 \mathrm{mi.u} / \mathrm{ml}$ \\
Day 2I & $0.0 \mathrm{mi.u} / \mathrm{ml}$
\end{tabular}

\section{Discussion}

Caeserean scar pregnancy is being reported more frequently and if not treated aggressively and quickly, may lead to excessive uterine hemorrhage, with resulting maternal morbidity and mortality.

\section{Various methods being used to treat this condition include:}

a. Scar Resection - Laparoscopic or Open resection.

b. Hysteroscopic resection of the pregnancy sac after vasopressin injection.

c. Hysterectomy, if patient is hemorrhaging profusely.

d. Methotrexate intramniotic injection in the scar pregnancy sac.

e. Systemic Methotrexate therapy.

f. Surgical uterine artery ligation.

g. Uterine artery embolisation. ${ }^{3-5}$

A simple algorithm has been given for management of caeserean scar pregnancy based upon the S.HCG level and the hemodynamic status of the patient. ${ }^{1}$ In our hospital we had 3 cases of caeserean scar pregnancy in 8 years. One patient had severe hemorrhage and went into hypovolemic shock when evacuation was tried, because of a wrong diagnosis of incomplete abortion. She was resuscitated and treated with systemic methotrexate therapy. In this patient the initial S.HCG level was below $10,000 \mathrm{miu} / \mathrm{ml}$ and the scar pregnancy completely resolved with methotrexate. The second patient had S.HCG level more than $10,000 \mathrm{miu} / \mathrm{ml}$. Systemic methotrexate was again tried as first line therapy, but as she kept hemorrhaging, she was finally managed with laparotomy and scar resection ${ }^{1}$ (Chart 1$)$.

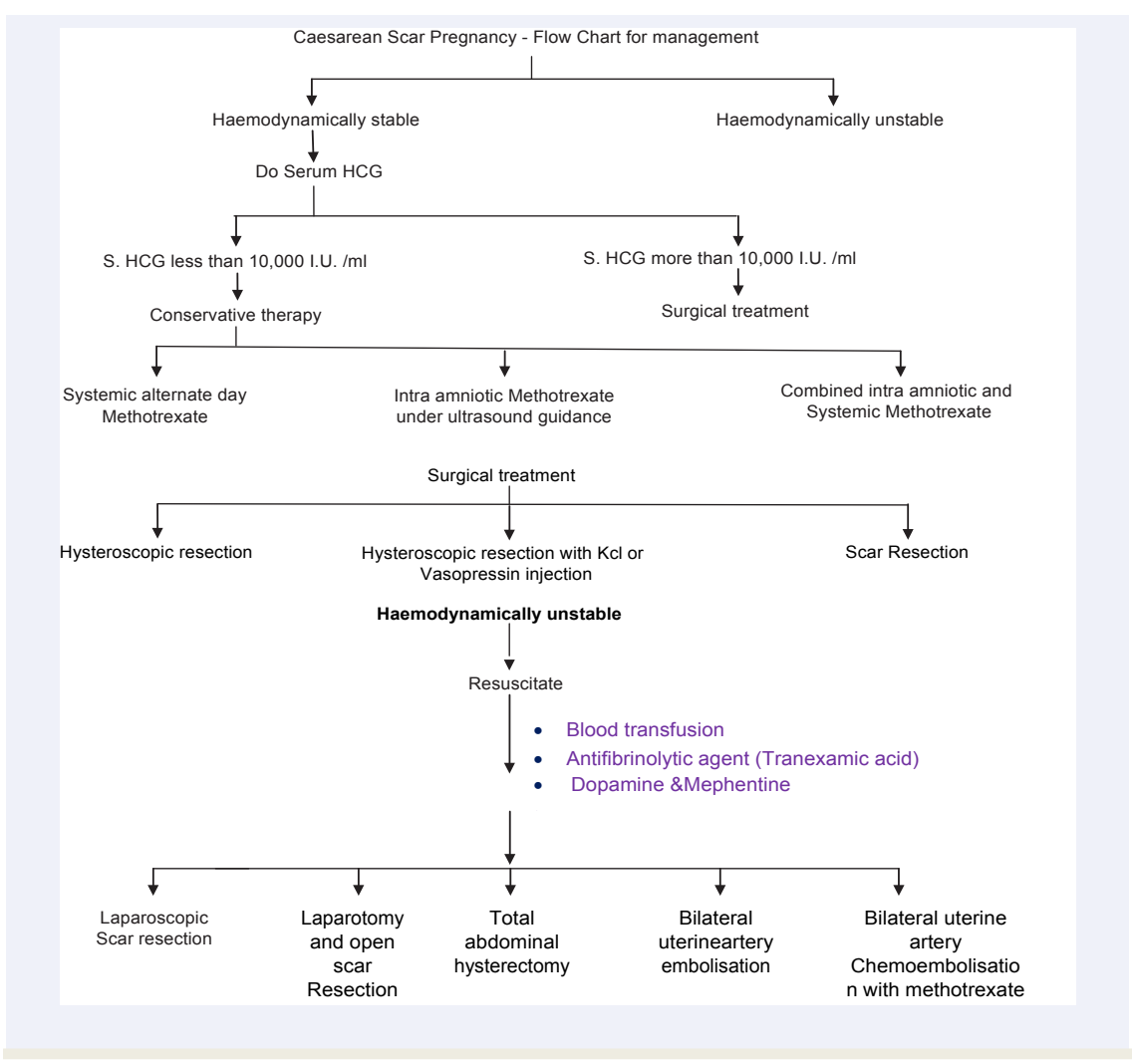

Chart I Chart showing algorithm for management of caesarean scar pregnancy. 
Methotrexate competitively binds to the enzyme dihydrofolate and prevents conversion of dihydrofolate to tetrahydrofolate, thereby inhibiting synthesis of deoxy ribonucleic acid. MXT hence inhibits cell proliferation in the actively dividing cells of trophoblast and also causes cytolysis of the earlier formed cells.

In a recent study methotrexate instilled into the gestation sac in caesarean scar pregnancy was compared with systemic MXT therapy. They found that the mean time for gonadotrophin normalization, uterine mass disappearance was less with local intragestational MXT instillation. They also opined that the dose of MXT instilled in gestation sac was much less as compared to that given in systemic therapy. However the cure rate was $100 \%$, and similar in both intragestational and systemic MXT therapy. ${ }^{6}$ In one case report, local intramniotic MXT was combined with uterine artery embolisation to control the hemorrhage. ${ }^{7}$ It is time now that with plenty of case studies and case reports regarding caesarean scar pregnancy available in literature, that standard guidelines and protocols should be formulated to bring uniformity in management of this serious condition.

\section{Conclusion}

Systemic Methotrexate therapy is a simple, safe and inexpensive technique for treatment of caeserean scar pregnancy in women who are haemodynamically stable and have S.HCG levels less than $10,000 \mathrm{miu} / \mathrm{ml}$.

\section{Acknowledgements}

None.

\section{Conflict of interest}

The author declares no conflict of interest.

\section{References}

1. Jain Deepti. Caesarean Scar Pregnancy managed by scar resection A case Report and Algorithm for management. JSM Clin Case Rep. 2013;2(1):1018.

2. Jurkovic D, Hillaby K, Woelfer B, et al. First trimester diagnosis and management of pregnancies implanted into the lower uterine segment cesarean section scar. Ultrasound Obstet Gynecol. 2003;21(3):220-227.

3. Mahgoub S, Gabriele V, Faller E, et al. Caeserean scar ectopic pregnancy. Laparoscopic resection and total scar dehiscence repair. A case report. $J$ Minim Invasive Gynecol. 2017;S1553-S4650(17):30098-30105.

4. Sharma Deepti, Usha MG, Krishanadas S. Successful treatment of a repeat Caeserean Scar Ectopic pregnancy with Transvaginal Intraamniotic instillation of Methotrexate. J Obstet Gynaecol India. 2013;63(3):209-210.

5. Shen L, Tan A, Zhu H, et al. Bilateral uterine artery chemoembolisation with methotrexate for cesarean scar pregnancy. Am J Obstet Gynecol. 2012;207(5):386.

6. Uludag SZ, Kutuk MS, Ak M, et al. Comparison of systemic and local methotrexate treatments in cesarean scar pregnancies: time to change conventional treatment and follow-up protocols. Eur J Obstet Gynecol Reprod Biol. 2006;206:131-135.

7. Tulpin L, Morel O, Malartic C, et al. Conservative management of a Cesarean scar ectopic pregnancy: a case report. Cases J. 2009;2:7794. 